\title{
Scholarly Advances in \\ Humanitarian Engineering and Social Entrepreneurship: A Typology of Research Publications
}

\author{
Rachel Dzombak* \\ Humanitarian Engineering and Social Entrepreneurship (HESE) Program \\ The Pennsylvania State University \\ University Park, PA 16802 \\ dzombak@gmail.com \\ Khanjan Mehta** \\ Humanitarian Engineering and Social Entrepreneurship (HESE) Program \\ The Pennsylvania State University \\ University Park, PA 16802 \\ khanjan@engr.psu.edu \\ * Currently an NSF Graduate Research Fellow, Dept. of Civil and Environmental Engineering, University of \\ California, Berkeley \\ ** Corresponding Author
}

Abstract: The rapid increase in academic and professional programs in Humanitarian Engineering and Social Entrepreneurship reflects a paradigm shift towards market-centric approaches to scale Appropriate Technology solutions for developing communities. Transdisciplinary academic frameworks that integrate teaching, research and entrepreneurial engagement can be pivotal in the development of such sustainable and scalable technology ventures. Engaging students in original, institution-approved, and publishable research can bolster their learning while strengthening the venture-creation process. Although the dissemination of knowledge (e.g. designs, business strategies, lessons learned, effective educational regimens) is desired by the growing community and is recognized as crucial to success, several systemic barriers impede the emergence of open and democratic scholarly forums. This article discusses the opportunities and challenges faced by students, faculty and practitioners in their quest for disseminating knowledge through scholarly channels. While the knowledge is extremely valuable, it cannot always be encapsulated and shared through conventional hypothesis-driven manuscripts. Consequently, academics and practitioners struggle to carve out and share aspects of their work that constitute scholarship and can potentially help other innovators. This article presents a typology of manuscript frameworks to illustrate the multiplicity of publication types that can collectively transform this exciting field into a rigorous, vibrant, and respected global community of engaged scholars and problem-solvers.

Index Terms - scholarship, research, publication, humanitarian engineering, social entrepreneurship 


\section{INTRODUCTION}

Humanitarian Engineering and Social Entrepreneurship (HESE) are emerging as compelling pathways to address the needs of developing communities while achieving high levels of academic engagement amongst undergraduate and graduate students. ${ }^{1,}$, 3 Humanitarian Engineering encompasses research and design efforts to improve the wellbeing of marginalized communities with technology-based solutions. ${ }^{4}$ While many academic programs have embedded experiential elements into their curricula, they vary greatly in rigor, epistemology, practice, and reach. ${ }^{5,6}$ Despite this variation, most programs share a common vision of developing solutions to confront compelling global challenges like natural resource management, healthcare, energy, employment, and food security. The integration of an entrepreneurial component into Humanitarian Engineering projects provides a mechanism for the validated technology solution to sustain, scale-up, and empower significantly more people. Student experiences in such programs range from short-term service activities to high-impact engagement that focuses on the development of sustainable and scalable technology ventures that prioritize social returns while being economically sustainable.

As programs in HESE strive for legitimacy, efficacy and impact, we argue that: first, engaging students in original, rigorous, institution-approved, and publishable research can bolster student learning and strengthen the ventures; second, engaging the community in research endeavors strengthens the venture-creation process and increases the potential for larger impact; and third, the knowledge created over the entire venture lifecycle is of practical importance to the larger community and must be shared in formal and informal ways. In support of these three arguments, this article discusses the importance, opportunities and barriers to scholarly dissemination of knowledge created through engagement in HESE endeavors. The goal of such research (and publication) endeavors is not limited to proving a hypothesis or finding the answer to a specific research question. Rather, the objective is to share knowledge that can inspire and inform other innovators working on similar global development challenges. Accordingly, there is a need to identify and articulate the various kinds of manuscript frameworks that can be used to capture and convey knowledge to a diverse community of faculty, students, practitioners and everyday innovators. This article presents a typology of eleven manuscript frameworks with the aim of lowering barriers to knowledge dissemination and diversifying scholarship.

\section{Student Engagement in Research}

As Humanitarian Engineering and Social Entrepreneurship become established as well-defined fields, conducting rigorous research presents several benefits. There is growing recognition of the value of evidence-based approaches to domestic and international development challenges. ${ }^{7}$ For instance, in the past decade, the fields of public health and medicine have sought to ensure that all development initiatives are backed by comprehensive knowledge generated by holistic research endeavors. ${ }^{8,9}$ When entrepreneurs discuss new ventures with potential partners and sponsors-be they from a community, academia, industry, government, or various funding agencies-evidence from past endeavors can be very compelling, especially if the idea or strategy being presented is supported by multiple publications. Additionally, the hands-on problem-solving nature of HESE affords a natural opportunity to engage students in scholarly research. Students benefit from engaging in research as it allows them to take a deep dive into pertinent topics and become subject-matter experts. Publications serve as tangible outputs of 
students' efforts while concurrently advancing the cumulative knowledge in the field. Needless to say, refereed publications make students stand out to future employers or graduate schools.

For example, the authors' program in HESE integrates learning, scholarly research, and entrepreneurial engagement. Such integration reflects the engaged scholarship increasingly called for in higher education, particularly among, but certainly not limited to, land grant institutions. ${ }^{10}$ HESE students work collaboratively with multi-sectoral partners to develop technology-based social ventures in resource-constrained environments. Ventures range from low-cost greenhouses and solar food dryers to telemedicine systems, rainwater harvesting systems, and cellphone-based social networking platforms. As students advance their ventures, they also work on related formal research studies approved by the university's institutional review board (IRB). The primary thrust of the program is on the ventures, with the research endeavors undertaken to inform and strengthen the ventures. Research areas include HESE education, systems thinking, social enterprise business models, access to capital and informal lending, indigenous knowledge systems, agricultural technologies, affordable biomedical devices, telemedicine systems, community health workers, science education, and cell phones and social Networks. The research agenda is dynamic and evolves with the needs of the technology ventures undertaken and partners' interests.

Making effective presentations and clearly articulating ideas is another essential skillset that students develop when they present at conferences and competitions. Since most of the HESE ventures need multiple years to mature, the research publications often help pass on materials from one team to the next. Often, the teams exhaust what they can accomplish by themselves and the publications help connect to the larger community and find collaborators. Participatory research helps uncover contextual details about how the venture might benefit the communities involved. Through its organic and qualitative approach, such research helps validate assumptions and gather relevant information to craft a venture's technology, business and implementation strategies. The publication strategy of the HESE program and lessons learned are summarized in the Appendix.

\section{Participatory Research}

Community-based participatory research is one avenue through which sustainable and impactful relationships can be built between academic institutions and marginalized communities. ${ }^{11}$ Such endeavors can validate and qualify the specific and systemic needs for a potential solution while expanding academic research agendas and enhancing student learning. Involving the community in research endeavors fosters a mutually beneficial relationship that ensures rigor and validity for the educational program while engaging communities in identifying their critical needs and collaboratively implementing sustainable solutions. ${ }^{12}$ Research prompts a critical assessment of proposed technological solutions, validates assumptions, and serves as a useful educational mechanism for all stakeholders. The contextual information gathered during early phases of a venture drives the design process and provides the necessary backdrop for the aggregation and dissemination of lessons learned. From a community standpoint, participatory research engenders pride and ownership in the project while building trust among the partners. Personal and business relationships in the developing world are based very strongly on trust and respect. Social capital arises from the existence of trust in this context and encourages cooperation among partners in the generation of economic and social value in the longer term. 
The concurrent praxis of research and entrepreneurship in resource-constrained environments presents several difficulties. Myriad barriers exist to conducting structured, controlled research in the chaotic, dynamic, and unpredictable circumstances inherent to entrepreneurship in developing countries. ${ }^{13}$ Often times, accurate information is inaccessible, partner expectations are not aligned, and conflicts of interest bias collaborative efforts. ${ }^{14} \mathrm{~A}$ review of the literature reveals that currently, technology designs, early-stage project outcomes, theoretical discourses, and descriptions of teaching strategies and curricular exercises compose the bulk of the publications related to HESE. Since technology-based social enterprise is nascent within the academic realm, educators and practitioners come from a wide variety of backgrounds, each with their own dominant epistemologies, research methodologies, philosophical frameworks, and publishing habits. While the kinds of publications emerging right now are highly valuable and should be continued with equal vigor, there is a need to further diversify the publication landscape. Diversification can, and should, occur through the integration of students and practitioners in this scholarly dialog. However, it is more important to diversify the types of publications that share valuable knowledge, and hence characterize scholarship, in HESE.

\section{The Publication Landscape}

To be classified as scholarly, peer-reviewed publications must meet certain standards like clearly articulating goals, adequate preparation, appropriate methods, significant results, effective presentation, and reflective critique. ${ }^{15}, 16$ Historically, the dissemination of new knowledge through publications has served as a means of advancing the field and gaining academic capital in the quest for tenured faculty positions. Although the proportion of non-tenure track faculty continues to grow relative to their tenured peers ${ }^{17}$, publishing in discipline-related journals continues to be the gold standard of professional accomplishment. Over time, many prestigious peer-reviewed journals have garnered a reputation for low acceptance rates, laborious acceptance processes and stifling articles that deviate from the rigid norms. ${ }^{18,19}$ Conventional academic journals are most comfortable with hypothesis-driven manuscripts with well-defined methodologies and positivistic epistemologies. In essence, they are forums for academics to write for other academics in precise language and jargon that articulates the new knowledge and its bounds. While such journals are extremely important, they do not always serve the needs of non-expert practitioners and innovators seeking practical insights to directly advance their work.

At the same time, authors of community-engaged scholarly work often struggle to find appropriate forums for publication. The knowledge generated and validated by practitioners and entrepreneurs is often considered inferior and their inability to articulate ideas in precise academic language makes it more difficult to find forums for dissemination and dialog. On one hand, the landscape is gradually changing with increasing numbers of journals emerging to serve the needs of engaged scholars and practitioners. At the same time, many changes are needed to improve and enhance scholarly publication. The lengthy timelines associated with manuscript submission prevent involvement by both, industry practitioners and undergraduate students. Unlike faculty, students rarely have the luxury of committing to a project over multiple semesters. Speeding up the peer-review process without compromising its integrity would create a more welcoming environment for all stakeholders. Another means of engaging practitioners could be requiring authors to seek industry input or requiring review boards to include industry members. Both tactics would help to bridge the gap between academics and practitioners. 
For many fields, like civil engineering, biochemistry, and physics, a large number of wellestablished and rigorous publication forums exist. On the other hand, HESE innovators have fewer forums and poorly-defined publication frameworks to reach peers engaged in similar activities. Some factors that impact scholarship in HESE include:

1. As much of the literature generated does not lend itself to a traditional hypothesis-based format, academics and practitioners alike struggle to carve out and share aspects of their work that both constitute scholarship and potentially help other innovators.

2. Limited graduate student funding along with a generally weak or nonexistent culture of undergraduate research and publication make it difficult for students to find mentors to assist in the manuscript development process. Since incentive systems primarily cater to tenure-track faculty, motivation to publish diminishes among non-tenured faculty, many of whom engage students in hands-on, experiential learning activities.

3. There is limited funding available to conduct applied research in developing countries. Data collection can be compromised when researchers don't have access to translators, transcribers or logisticians to facilitate their work. Studies are conducted in a fragmented manner and as time drags on, it gets increasingly difficult to get the manuscript completed.

4. Particularly for faculty working in the realm of entrepreneurship, venture-creation activities and research endeavors seldom overlap. While their journeys and lessons learned can be extremely useful and inspiring, entrepreneurs have little incentive to engage with a scholarly community. Would an entrepreneur prefer to write an engaging blog post, give a talk, or write a formal scholarly paper that provides evidence and discusses every minute detail with references?

5. Institutional Review Board (IRB) requirements (for studies that involve human subjects) are often times overly complicated and not relevant to the work of entrepreneurship, leading many to either not conduct research or conduct research without IRB approval. Unfortunately, failure to gain IRB approval renders studies ineligible for publication. At the same time, the development of the IRB protocol is an excellent learning experience for students as it forces them to think through, and plan, every small detail of the study.

Traditionally, research is conducted in carefully-controlled environments. While a laboratory setting may be quickly described or assumed, chaotic developing country contexts require longer and more extensive explanations than normally allowed in traditional publications. The research findings tend to be very specific to the context and while they may be highly-transferrable, they cannot always be considered generalizable knowledge. This makes it even more difficult to carve out the valuable findings and share them in traditional journals. Another issue lies in the fact that industry practitioners, especially in the developing world, engage in scholarly conversations to a minimal degree. With no financial incentives to publish, individuals working in industry devote their time to pursuing business endeavors. If engagement with academics does occur, it is usually at relevant conferences, which allow for networking and provide an opportunity for industry leaders to stay current with the state of the art and science. The experiences of practitioners can greatly benefit students and faculty members alike and thus finding practical approaches to facilitate their participation in a scholarly forum is crucial for the development of rich and dynamic forums. To promote the creation of a coherent body of literature in the broad-reaching fields discussed in this paper, we have presented the diverse forms of scholarly publications that 
can contribute towards this goal. For larger discussion on publications and scholarship, see the following sources. $16,20,21$

\section{MANUSCRIPT FRAMEWORKS}

This section presents a typology of frameworks for scholarly manuscripts. This typology does not include every potential manuscript framework, and these frameworks must not be considered plug-in templates. Each framework includes a description, a flowchart, and an example of a manuscript that would advance scholarship and lead to greater socio-economic impact. The intent of the examples is solely to illustrate the application of the manuscript frameworks; their resemblance to actual published papers is coincidental and unintentional.

\section{Scientific: Hypothesis Driven Manuscript}

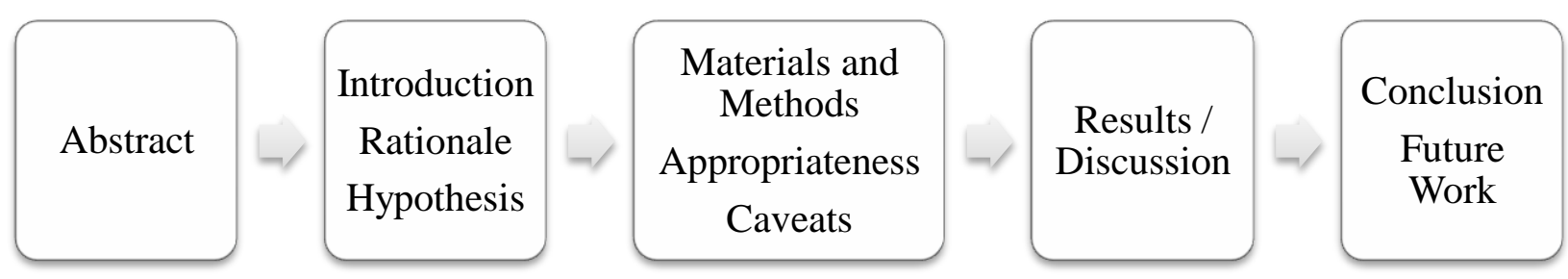

FIGURE 1

\section{OUTLINE OF A SCIENTIFIC: HYPOTHESIS DRIVEN MANUSCRIPT}

Hypothesis-driven manuscripts (Figure 1) are developed on the basis of controlled experiments that seek to confirm or deny a stated hypothesis. Hypotheses presented should be concise, unambiguous, and able to be tested through defined, repeatable methods. Additionally, assumptions must be stated meticulously, pointing out context-specific variables and those unaffected by location. For example, one cannot broadly state that a product was designed "for Africa." Instead, the context must be nuanced through a description of defining characteristics of the target population. Some ventures demand human subject research, which necessitates prior approval from an Institutional Review Board. ${ }^{13}$ As controlled research is often incompatible with the chaos inherent to developing countries, it is important to discuss the caveats of the methodology and their impact on the results. Fundamental research can be replicated but, in this setting, experiments have to be adapted to fit the context. Additionally, authors of hypothesisdriven papers must perform statistical analysis ( $\mathrm{p}$-value determination, standard deviation of means, etc.) on their results. A description of appropriateness encompasses clarifying the context in which the study was conducted. While the intricate details of the context and author experiences are valuable, the results and statistical analysis should be the focus of the paper.

Example: After completing the prototype of a solar-powered lantern (SPL), an innovator assesses ten commercially-available lanterns to prove superior visible light production of her SPL. To accomplish this, the innovator designs an experiment to measure the luminous efficacy of each lantern in a dark room. Once complete, she conducts statistical analysis to determine the 
significance of the results. When writing up the results for publication, the innovator must include the detailed procedure and protocols so that anyone can reproduce the results. Further, she must provide evidence from literature that her methods were an appropriate means of capturing the intended metrics.

\section{Scientific: Non-Hypothesis Driven Manuscript}

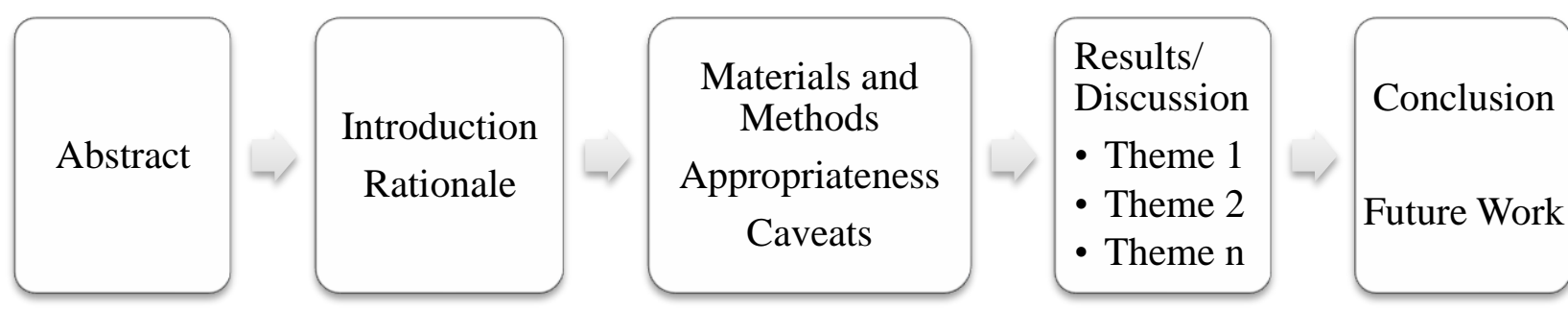

FIGURE 2

\section{OUTLINE OF A NON-HYPOTHESIS DRIVEN MANUSCRIPT}

Instead of proving a hypothesis, a scientific non-hypothesis driven manuscript (Figure 2) presents preliminary results for a series of open-ended questions. Exploratory studies are often open-ended and begin with a broader question that motivates the investigation but the specific research questions (or hypotheses) cannot be determined in advance. Often, once the data are collected, a search and discovery process is employed to identify and articulate the value of the information. The results and discussion can encompass multiple themes (patterns) of results that emerged during the research endeavor. It is important in papers not guided by an overarching hypothesis to identify a strong focus of the research. This helps to identify measures through which triangulation of data can be accomplished. Even though statistical significance is not a major focus of exploratory studies, the data must be verified by other sources. This can be accomplished through a search of relevant literature. In the conclusions of a paper, one may want to discuss potential hypotheses that could be studied at a later time. This manuscript format is useful when writing about pilot projects. Conducting assessment and analyzing pilot project data can provide insight into project achievements and shortcomings.

Example: While working with a non-profit in Nairobi over five years, an innovator observes how functional street lights along with businesses open until later at night led to an exponential decrease in crime rate in the central business district. He resolves to replicate this success story in other small towns of Kenya. He commences design on a low-cost solar-powered street light and initiates a study to identify which small businesses can benefit from the lights. He spends a month conducting individual interviews and focus groups with community members and business owners to understand community needs and potential challenges to venture implementation. The innovator develops a manuscript with three themes: 1) factors influencing lighting hours, 2) post-sunset business opportunities and 3) potential sources of funding for capital and routine maintenance expenses. These findings directly inform his product design and business strategy. At the same time, the manuscript informs other entrepreneurs about the opportunities and challenges with undertaking similar ventures that can reduce crime and advance socio-economic development in other communities. 


\section{Literature Review}

Literature reviews (Figure 3) synthesize published information in a particular subject area. It may reinterpret previously discussed material or combine new insights with old interpretations. A literature review can identify major debates in a field, provide an overview of the current state of the field, and attempt to delineate new trajectories for further research. The purpose of a literature review is to organize and synthesize published articles. For academics and practitioners who want to stay up-to-date with current research, literature reviews are invaluable. When writing a literature review on topics relevant to humanitarian engineering and social entrepreneurship, the sources may be pulled from an array of disciplines, but the author must strive to maintain a coherent focus and storyline. Additionally, since relevant literature often crosses disciplinary boundaries, it is critical to gather and connect these diverse perspectives and philosophies. The recent advent of cellphones and the internet have fundamentally impacted the creation, validation, application, and dissemination of knowledge. This globalized state of our world opens myriad opportunities for older literature, designs and perspectives to be revisited, retrofitted, rethought and re-applied to current realities.

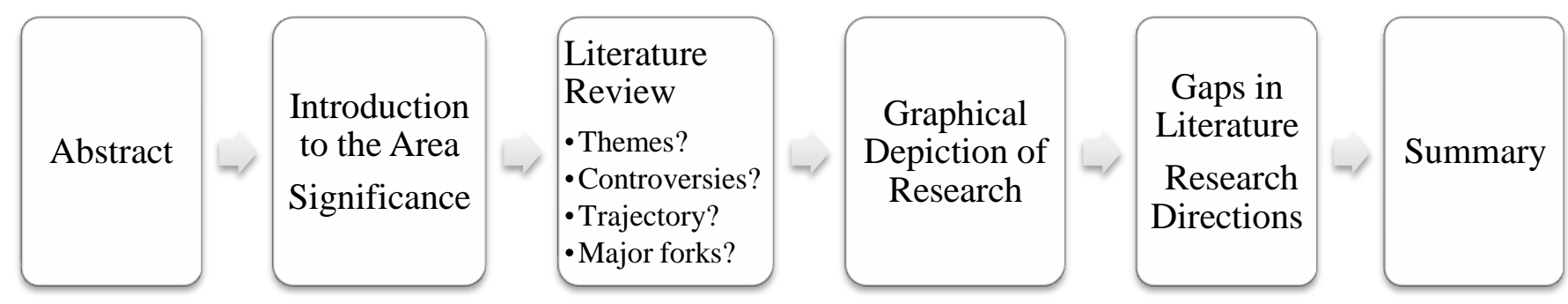

FIGURE 3

OUTLINE OF A LITERATURE REVIEW

Example: An innovator is attempting to develop affordable solar-powered lanterns for communities in the hilly and foggy areas of northern Thailand. In her quest for a feasible solution, she discovers that several low-cost solar panels have been used in diverse terrains with mixed results. She undertakes a careful study of the solar power systems employed in foggy regions, socio-economic traits of the users and the business strategy adopted by the entrepreneurs. She prepares a manuscript that provides a comprehensive analysis of the engineering design and business strategy decisions made by the entrepreneurs in this specific context. Several themes emerge from this study like the importance of material selection and the financial reliability of women's groups operating the lantern charging stations. This manuscript then guides entrepreneurs in appropriate design and partner identification. Researchers can see larger patterns emerge from this study that form the nucleus of new theoretical models of technology dissemination. In essence, this manuscript could be considered a literature review, or more appropriately, a review of praxis. 


\section{Typology / Taxonomy}

Typologies (Figure 4) are a means of organizing and retrieving content like concepts, approaches, technologies, and business models. ${ }^{22}$ The means of organization in a typology can be based on a variety of factors including observations, defining attributes, and quantitative measures like cluster analysis. Additionally they can encompass naming sequences in order to infuse clarity and accessibility into an esoteric topic. Taxonomies have a stricter format and typically exist as "empirically derived, hierarchical system(s)." ${ }^{22}$ For manuscripts of this form, it helps to present the typology/taxonomy in words and graphically, to ensure readers understand the methodology presented and how to use it. The strength of a typology or taxonomy lies in its usability, and their value can be bolstered through examples, case studies, and descriptions of validation efforts.

\begin{tabular}{|c|c|c|c|c|c|c|c|c|c|c|}
\hline Abstract & -1 & $\begin{array}{l}\text { Introduction } \\
\text { to the Area } \\
\text { Significance } \\
\text { Application }\end{array}$ & $-d$ & $\begin{array}{c}\text { Typology } \\
\text { Assumptions } \\
\& \\
\text { Conventions } \\
\text { Type } \\
\text { Relationships } \\
\text { (Diagram) }\end{array}$ & - & $\begin{array}{l}\text { Typology } \\
\text { - Diagram } \\
\text {-Explanation } \\
\text { - Case Study? } \\
\text {-Examples? } \\
\text {-SWOT? } \\
\text { - Deeper } \\
\text { content? }\end{array}$ & -1 & $\begin{array}{l}\text { How to use } \\
\text { the } \\
\text { typology? } \\
\text { Caveats }\end{array}$ & - & Summary \\
\hline
\end{tabular}

\section{FIGURE 4 \\ OUTLINE OF A TYPOLOGY}

Example: An innovator is working on a venture focused on solar-powered lanterns for domestic use in Haiti. Several different dissemination models have been field-tested for solar lanterns and he is not sure which approach would be most appropriate for this setting. He undertakes an exhaustive internet and literature search of dissemination strategies and meticulously categorizes the approaches based on the stakeholders, sources of capital funding, sustainability mechanism, geographical context, etc. He conducts an analysis of the Strengths, Weaknesses, Opportunities and Threats (SWOT) for each approach. Finally, he develops a typology of twelve distinct dissemination strategies with a discussion on their relative SWOTs and their appropriateness for various cultural and contextual settings. This typology helps other innovators in their quest to find the most appropriate dissemination strategy for their specific context and stakeholder needs. 


\section{Theoretical Model}

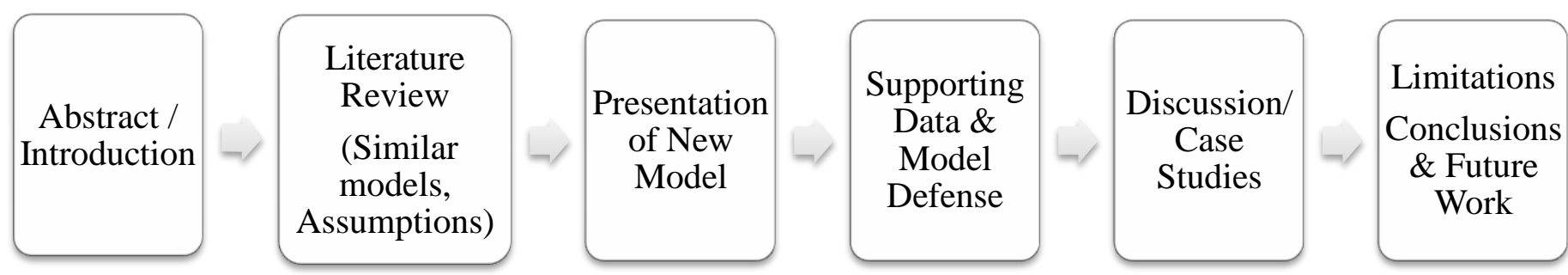

FIGURE 5

OUTLINE OF A MANUSCRIPT INTRODUCING A NEW THEORETICAL MODEL

Manuscripts of this form present a new method/model of analyzing a topic or understanding a pre-existing system. In a field attempting to become "mainstreamed", theoretical models (Figure 5) are important as they can be applied to a variety of endeavors, lead to the development of new ideas, and reinforce the rigor and legitimacy of the field as a whole. ${ }^{23}$ The paper should contain a rationale or explanation for the following: 1) why a new model is needed 2) how the model was developed 3) how the authors intend for it to be used 4) limitations of the model. To validate the model, an explanation of how the model was tested and refined should also be provided.

Example: Developing countries, with weak regulatory bodies and high degrees of corruption, struggle to control the counterfeiting of products. An innovator is using 3D printing to create a solar-powered lantern for use in India. She realizes that counterfeit products could severely impact her future success but struggles to explain the problem to local authorities. She develops a mixed-methods model to estimate how counterfeiting can impact small enterprises in different social, economic, regulatory and political contexts. Her model is able to predict revenues losses with a reasonable margin or error. She quickly discovers that her model also works for other consumer products. She decides to share the model with other entrepreneurs and also with academic experts so that it can be refined and generalized further. In her manuscript explaining the model, she effectively explains "small business" and provides case studies of small enterprises in China, India, and the US. The cases studies show how the variables can be adjusted based on context and how the impacts of counterfeiting vary according to location. Finally, she presents the limitations of the model, advises on future research direction, and provides her opinion on how it can be adapted for future use by others. 


\section{Challenges and Opportunities Manuscript}

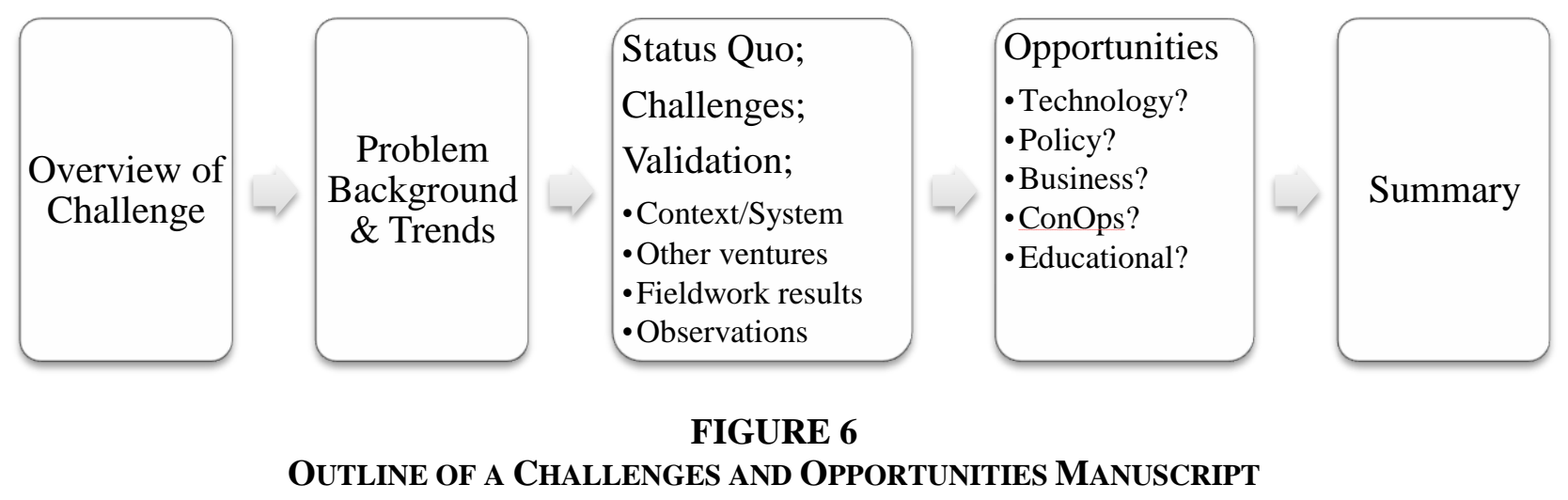

The discussions contained within manuscripts of this type (Figure 6) are a call to action and describe challenges related to a larger problem/context as well as the opportunities for value creation. The manuscript presents the current status of a situation, provides contextual/systemic information and suggests means of improvement. It can be focused on challenges, opportunities or both. It To provide a comprehensive analysis of the challenges and opportunities, it is important to seek guidance from diverse disciplines, and social scientists in particular, to paint a valid picture of the socio-economic context. Such manuscripts can benefit from a systems perspective that juxtaposes the root causes of challenges with specific symptoms and manifestations. Manuscripts of this type could include a glossary of resources to aid entrepreneurs as they respond to the call to action and strive to develop appropriate sustainable solutions.

Example: In an effort to address the Millennium Development Challenges, Bangladesh has committed to doubling the number of trained midwives in rural communities. However, few women want to become midwives because of the risks involved with traveling at night to deliver a baby. An innovator sees this as an opportunity to commercialize solar-powered lanterns that can be charged in the daytime and used at night. He conducts a research study and paints a comprehensive picture of the systemic challenges to providing solar-powered lanterns to midwives. Within his manuscript, he also details trends in both midwifery and lantern availability, proposed benefits of this initiative to the various stakeholders, potential for scalability, and practical mechanisms through which lantern distribution could be accomplished. This manuscript informs and inspires innovators to develop effective solutions to this compelling set of challenges. 


\section{Lessons Learned/Best Practices}

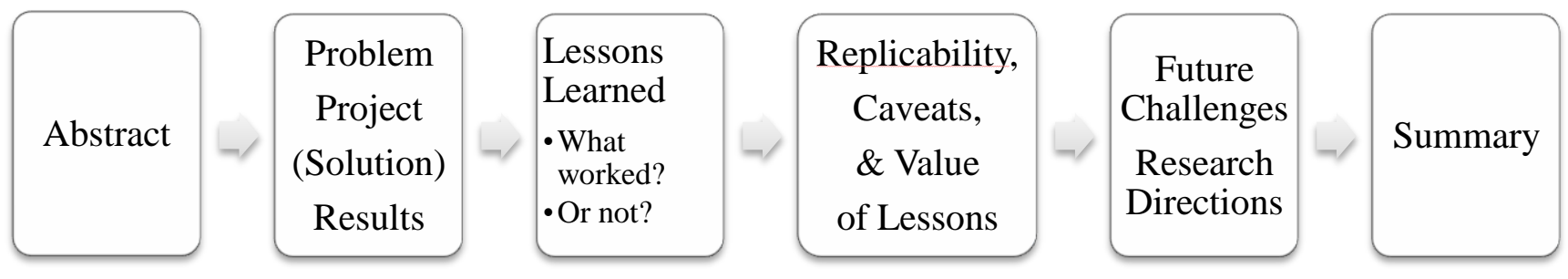

FIGURE 7

\section{OUTLINE OF A LESSONS LEARNED / BEST PRACTICES MANUSCRIPT}

Lessons learned papers (Figure 7) allow individuals to share experiences with colleagues. Topics can include lessons from successes as well as failures. Many humanitarian engineering and social entrepreneurship ventures share similar problems. By publishing best practices, individuals new to the field can learn from successes and failures of past endeavors. This paper format also provides an opportunity to engage practitioners in the field who are resistant to writing papers due to the necessary time commitment and lack of incentive. However, their omission renders the body of literature sub-optimal and incomplete. It is important to note that not all work merits a lessons learned paper; the developed manuscript must provide either deeper insights on old lessons, build upon comparable lessons, or report practices entirely unique. A discussion of the endeavor that yielded the lessons is crucial, as is a sketch of the author's personal and professional background and experiences that qualifies her to synthesize and share her lessons learned.

Example Paper: An innovator working in a Zambian community introduced solar-powered lanterns and managed to scale usage rates from $1 \%$ to $80 \%$ in three different communities over two years. The mean population of each of these communities was 20,000 people. As she prepares to scale from three communities to twenty, she develops a lessons learned manuscript to disseminate the knowledge she gained to others as well as hone her organization's strategy moving forward. The manuscript includes discussion of design attributes, business strategy, and viral marketing methods that propagated success. She also discusses hurdles faced along the way. Finally, she generalizes some of the steps she took in order to make them relevant and usable to other entrepreneurs.

\section{Design Tenets}

A design tenets manuscript (Figure 8) explains how to construct a product or describes guiding principles for a technology product. Often the tenets alone will be published (depending on the author's intellectual property strategy) or sometimes the detailed blueprints might be placed in the public domain. The actual construction manual can be included in the appendix or alternatively be made available on a website. Articles on design tenets are helpful to social entrepreneurs as they place the technology in the public domain and establish it as prior art. This gives them the freedom to operate and prevents other entities from patenting the product. The design or design tenets alone, however, are only one aspect of value in this genre. Field-testing results, market potential, customer perspectives, and commercialization strategies can further enrich such manuscripts. 

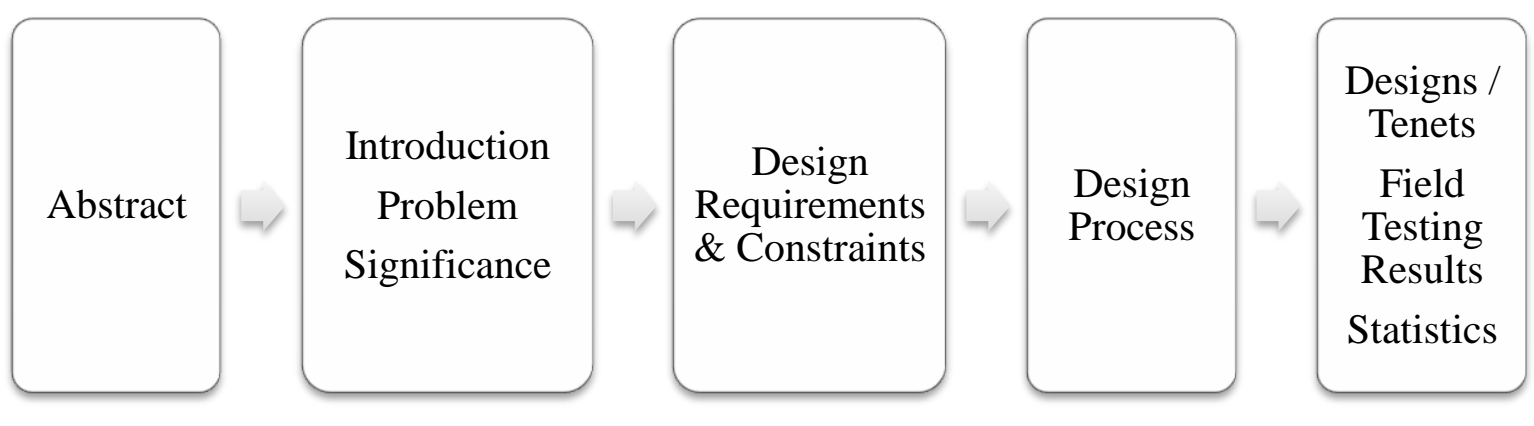

Business
Strategy
Tech
Maturity
Level
Next
Steps

\section{OUTLINE OF A DESIGN TENETS MANUSCRIPT}

Example: Most solar-powered lanterns are made of plastic and metal and cannot be recycled after they are decommissioned. An innovator designs a bamboo lantern for rural China. The lantern is based on the principles of cradle-to-cradle design and is completely recyclable. The innovator publishes a paper with detailed design specifications and instructions on how to build a lantern with bamboo and other organic components. The manuscript also discusses methods of product quality testing, troubleshooting and maintenance of the lantern. The instruction manual is very visual in nature so that individuals with limited educational backgrounds or those from different cultures can easily build their own lanterns. The final section of the manuscript discusses how enterprising individuals can start a cottage industry manufacturing and selling these bamboo lanterns.

\section{Educational Tool}

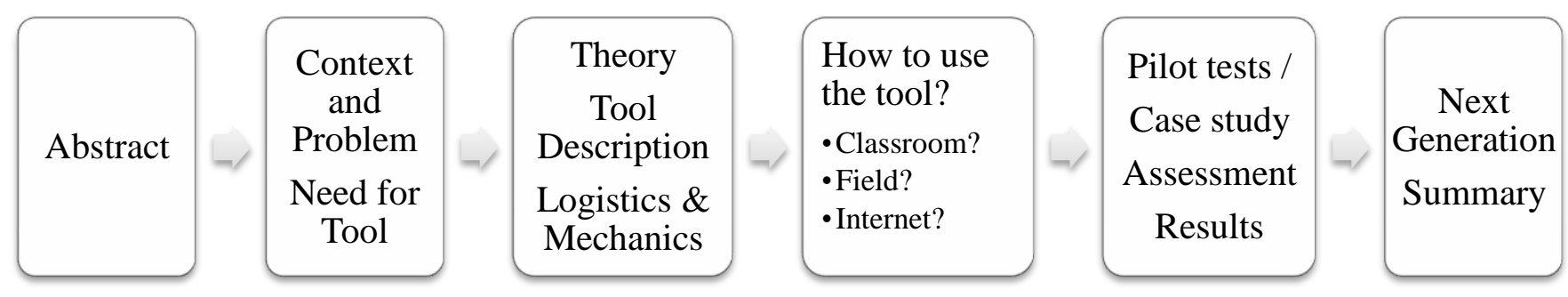

\section{FIGURE 9}

\section{OUTLINE OF A MANUSCRIPT INTRODUCING AN EDUCATIONAL TOOL}

There exists a need for educational pedagogies and tools that introduce intricacies of diverse cultures and contexts to aspiring innovators. As part of educational programs focused on international development, students must learn to empathize with the stakeholders and their context before they commence fieldwork. Since travel components of courses are often costprohibitive, the experiential education must be made "real" within the classroom. Educational tools to prepare students for engagement set the stage for deeper collaboration with community members, as such a dialog would help to ensure the most pertinent information and greatest needs and resources are discussed. A paper describing an innovative educational (participatory/field) activity or tool (Figure 9) should be accompanied with assessment data validating its efficacy. Methods of assessment must be rigorous and conducted with IRB approval over a sufficient period of time. Including an instructor's guide in the paper's appendix would lower barriers for other educators to refine and adapt the tool for their own classrooms. 
Example: An academic innovator designs an educational activity that enables students to experience life without domestic lighting. After testing the activity in her course thrice, she is convinced of its efficacy in helping her students empathize with their target customers and concurrently inspiring them to develop solutions. In order to assess the efficacy of this activity, she conducts focus groups and interviews with the students. She also requires the students to document their design decisions and then she identifies the design decisions that owe their genesis to the educational activity. Armed with these data, she publishes the rationale, learning objectives, logistics and assessment results of the educational activity. She candidly discusses the caveats of the activity - things that didn't work well - as well as the unanticipated outcomes. Finally, she provides practical insights to other educators who might be interested in adapting the activity.

\section{Essay or Opinion Piece}

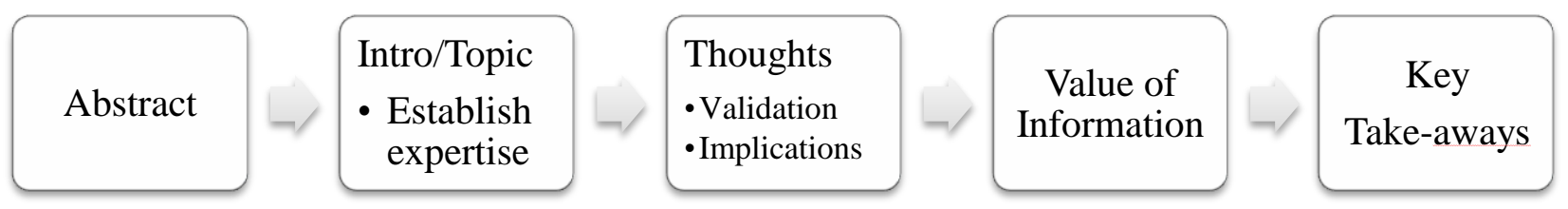

FIGURE 10

OUTLINE OF AN ESSAY OR OPINION PIECE

Opinion pieces (Figure 10) are informal, concise articles that seek to generate discussion on a given topic. Essays, or feature articles, are longer than opinion pieces but still relatively brief. Both of these frameworks allow for the presentation of information unsupported by empirical evidence but still important to the field of research or engagement. The introduction of essays and opinion pieces must convey the author's credibility as an expert, or at least a valid contributor, on a specific topic. Opinion pieces can cover a broad spectrum, from the history of a field to advances on the cutting edge, to future directions. Opinion pieces are typically not subjected to a peer review process and are published at the editor's discretion.

Example: An innovator is working on the design and commercialization of biomedical devices in East Africa. Several technologies designed by his team are currently used by hundreds of doctors in Kenya, Tanzania and Uganda. In spite of his track record and successes, several large foundations are turning down his proposals for funding because they insist that innovators must form on-the-ground educational collaborations. In east Africa there is not a single university with a program in Biomedical Engineering, and an equitable collaboration is not possible. The opinion piece brings this issue to light. In his article, he establishes his credibility by delineating his experiences and successes in east Africa. He provides rational arguments and personal perspectives and experiences on the impracticality of mandating certain kinds of collaborations. Finally, he suggests means through which the problem can be addressed and identifies alternate approaches that foundations can employ to ensure that there are adequate and equitable local partners to ensure project ownership and success. 


\section{Case Study}

Practitioners and academics often record, review and analyze specific situations, events, or experiences through case studies. Once published, they serve as valuable educational tools for others attempting to engage in similar endeavors. Case studies (Figure 11) can bring theoretical situations to reality and serve as a foundation for class discussion. They encourage students to communicate complex ideas and foster the development of decision-making skills. When approaching a study, students must realize that, just as in reality, absolute right or wrong answers do not exist in every situation. ${ }^{24}$ Additionally, case studies identify components of success, indicators of failure, and gaps in research. For authors, publishing case studies develops new perspectives on past experiences and could lead to a lessons learned paper!

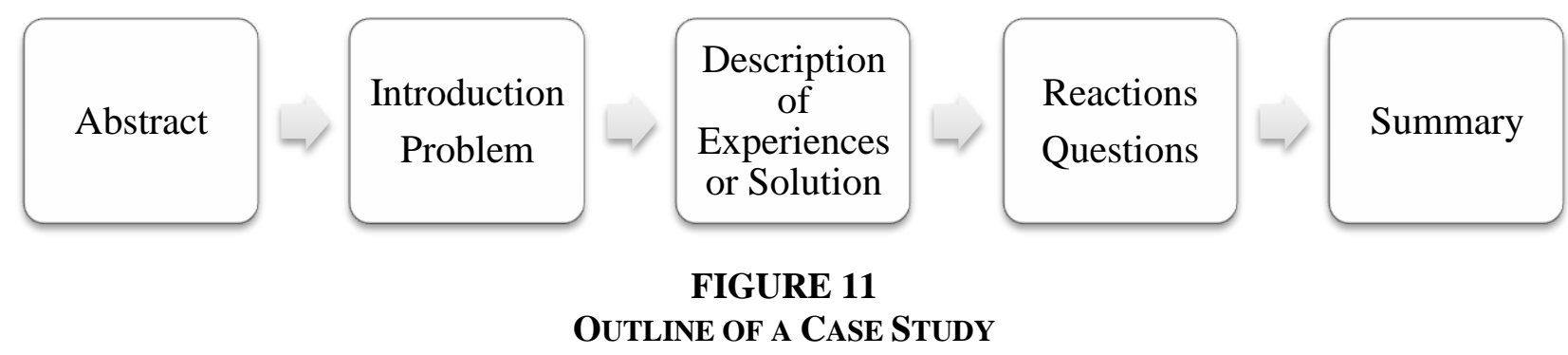

Example: An innovator realizes that an untapped market exists for solar-powered lanterns in low-income US communities. She develops a solar lantern venture in Appalachia but struggles to connect with local leaders and gain their trust. Ultimately, as she integrates more into the community, participates in local events, and goes to church with them, the trust issues gradually dissipate, and her venture becomes more successful. The innovator believes that other entrepreneurs and communities could benefit from her entrepreneurial experiences. She writes a manuscript that discusses both her failures and successes: her journey from her early validation to the eventual success of the venture and ongoing activities. In a frank and detailed manner, she discusses the technology solution, the barriers to acceptance, challenges to scaling operations and social dynamics that impacted her venture.

\section{Conclusion}

This article presented a typology of research manuscripts that can collectively advance engaged scholarship in the emerging domains of Humanitarian Engineering and Social Entrepreneurship. An increased number of forums and rigorous application of publication frameworks like those presented in this paper will help create a mainstream body of knowledge and lead to increased knowledge-sharing and greater degrees of collaboration among multi-sector partners. While only some of the knowledge will be generalizable across larger populations and contexts, the transferability of knowledge is a more important metric of success. Scholarly conversations are rendered incomplete without the active participation of people from various disciplines, cultures, and ways of thinking and doing, with a common shared interest in developing and using technology to create sustainable and scalable value. It is imperative that these fields increase the rigor, credibility, and impact of the work being pursued. Doing so will attract and engage more faculty and students, and lead to a more vibrant, global ecosystem of engagement in HESE. In 
essence, recognizing and elevating the scholarship in HESE is a win-win proposition for all stakeholders, be they students, faculty, communities, entrepreneurs, development organizations, and society as a whole. The eleven manuscript frameworks delineated in this paper contribute to the goals mentioned at the outset: greater student engagement in research and publication, participation by communities, and practical, synergistic alignment between the theory, praxis and impact of Humanitarian Engineering and Social Entrepreneurship.

\section{REFERENCES}

[1] J. Kickul, M. Griffiths and S. Bacq, "The boundary-less classroom: extending social innovation and impact learning to the field," Journal of Small-Business and Enterprise Development, vol. 17, no. 4, pp. 652-663, 2010.

[2] S. Hines, "The practical side of liberal education: An overview of liberal education and entrepreneurship," Peer Review, vol. 7, no. 3, pp. 4-7, 2005.

[3] K. Passino, "Educating the Humanitarian Engineer," Journal of Science and Engineering Ethics, vol. 15, no. 4, pp. 577-600, 2009.

[4] D. Munoz and C. Mitcham, "Humanitarian Engineering," in Convergence: Philosophies and Pedagogies for Developing the Next Generation, T. Colledge, Ed., 2012.

[5] J. Lucena, C. Mitcham, J. Leydens, J. Munakata-Marr, J. Straker and M. Simoes, "Theory and Practice of Humanitarian Ethics in Graduate Engineering Education," in American Society for Engineering Education, 2007.

[6] B. Amadei, R. Sandekian and E. Thomas, "A Model for Sustainable Humanitarian Engineering Projects," Journal of Sustainability, vol. 1, no. 4, pp. 1087-1105, 2009.

[7] S. Miller, N. Sloan, B. Winikoff, A. Langer and F. Fikree, "Where Is the "E" in MCH? The Need for an Evidence-Based Approach in Safe Motherhood," Journal of Midwifery \& Women's Health, vol. 48, no. 1, pp. 10-18, 2003.

[8] C. Eriksson, "Learning and knowledge-production for public health:a review of approaches to evidence-based public health," Scandanavian Journal of Public Health, vol. 28, no. 4, pp. 298-308, 2000.

[9] C. Victora, J. Habicht and J. Bryce, "Evidence-Based Public Health: Moving Beyond Randomized Trials," American Journal of Public Health, vol. 94, no. 3, 2004.

[10] Kellogg Commission, "Returning to our Roots: The Engaged Institution," National Association of State Universities and Land Grant Universities, Washington D.C., 1999.

[11] J. Schneider, J. A. Leydens and J. Lucena, "Where is 'Community'?: Engineering Education and Sustainable Community Development," European Journal of Engineering Education, vol. 33, no. 3, pp. 307-319, 2008.

[12] K. Mehta, "The Philosophy and Praxis of Convergence to Shape an Emergent High-Impact Learning Through Service Program," in Convergence: Philosophies and Pedagogies for Developing the Next Generation, T. Colledge, Ed., 2012.

[13] C. Bell, R. Dzombak, T. Sulewski and K. Mehta, "Preparing and Complying with Institutional Review Board Protocols for Integrated Research and Entrepreneurship Ventures in Developing Countries," Journal of Ethics and Entrepreneurship, vol. 2, no. 1, pp. 21-35, 2012.

[14] A. Grzybowski, B. Mathias and K. Mehta, "When Participatory Research and Business Strategy Collide: Lessons from Base-of-Pyramid Ventures," in NCIIA Annual Conference, 2012. 
[15] L. Richlin, "Scholarship of Teaching," New Directions for Teaching and Learning, vol. 31, no. 5, pp. 10-15, 2002.

[16] C. Glassick, M. Huber and G. Maeroff, Scholarship Assessed: Evaluation of the Professoriate, Jossey-Bass, pp. 36, 1997.

[17] E. Anderson, “The New Professoriate: Characteristics, Contributions and Compensation," in American Council on Education, 2002.

[18] B. Frey, "Publishing as Prostitution - Choosing between one's own ideas and academic success," Journal of Public Choice, vol. 116, no. 1-2, 2003.

[19] W. Starbuck, "How Much Better Are the Most-Prestigious Journals? The Statistics of Academic Publication," Journal of Organization Science, vol. 16, no. 2, pp. 180-200, 2005.

[20] P. J. Seldin, E. Miller and C. A. Seldin, The Teaching Portfolio: A Practical Guide to Improved Performance and Promotion/Tenure Decisions, Jossey-bass, 2010.

[21] A. Brew, The Nature of Research: Inquiry into Academic Contexts, Routledge Falmer, 2001.

[22] P. Rich, "The Organizational Taxonomy: Definition and Design," Academy of Management Review, vol. 17, no. 4, pp. 758-781, 1992.

[23] A. Nicholls, "The Legitimacy of Social Entrepreneurship: Reflexive Isomorphism in a PreParadigmatic Field," Entrepreneurship Theory and Practice, vol 34, no. 4, pp. 611-633, 2010.

[24] C. Agryris, "Some limitations of the case method: Experiences in a management development program," The Academy of Management Review, vol. 5, no. 2, pp. 291-298, 1980. 


\section{APPENDIX \\ HeSE@Penn State: Publication Throughput And APProach}

HESE students are mentored to publish their original work in peer-reviewed journals and conference proceedings. Table 1 summarizes the publication throughput from the HESE program from 2008 till date. The next set of $\sim 15$ research projects will be initiated in January 2014 . The research and publication processes are tightly integrated into HESE coursework. Students enroll in a post-travel class on HESE Reflection and Research Dissemination that has three themes of Ethical Decision-Making, Grassroots Diplomacy, and Research Dissemination. (Course website: https://sites.google.com/site/heserrd/) The Research Dissemination theme provides students with just-in-time information and skill-sets necessary for converting their concepts, data, and models into manuscripts. This is accomplished through a series of learning modules on the publication process, framing manuscripts, conducting and writing literature reviews, choosing a publication forum, navigating the peer-review process, data analysis and visualization techniques, plagiarism \& self-plagiarism, paraphrasing techniques, rules of referencing, and authorship issues. The faculty mentors directly supervise the research projects and development of the manuscripts. As co-authors, they have a vested interest in ensuring that the manuscripts are of good quality and are ready for submission to conferences and journals. Past students and external advisors are engaged in critiquing manuscripts or even co-authoring them with student leads.

TABLE 1

HESE PUBLICATIONS 2008-PRESENT

\begin{tabular}{|l|r|r|r|r|r|}
\hline & Published & In Press & $\begin{array}{c}\text { Under } \\
\text { Review }\end{array}$ & \multicolumn{1}{c|}{ In Prep } & \multicolumn{1}{c|}{ Total } \\
\hline Undergraduate Lead Author & 26 & 4 & 19 & 18 & 67 \\
\hline Graduate Lead Author & 11 & 1 & 6 & 8 & 26 \\
\hline Faculty Lead Author & 16 & 2 & 0 & 1 & 19 \\
\hline Total & $\mathbf{5 3}$ & $\mathbf{7}$ & $\mathbf{2 5}$ & $\mathbf{2 7}$ & $\mathbf{1 1 2}$ \\
\hline Conference Proceedings & 30 & 0 & 1 & 0 & 31 \\
\hline Journal Articles & 21 & 7 & 24 & 26 & 78 \\
\hline Book Chapters & 2 & 0 & 0 & 1 & 3 \\
\hline
\end{tabular}

*A list of HESE publications can be accessed through: http://www.hese.psu.edu

Primary conferences attended by students in the HESE program include the National Collegiate Inventors and Innovators Alliance (NCIIA) Annual Meeting and the IEEE Global Humanitarian Technology Conference. A few articles have been presented and published in the proceedings of the American Society for Engineering Education (ASEE) Annual Conference, Mobiles 4 Development (M4D) Conference, Information and Communication Technologies for Development (ICT4D) Conference and other miscellaneous forums. On one hand, conferences provide students an excellent professional development opportunity by enabling a face-to-face conversation about the article. At the same time, conferences tend to get very expensive and are not given as much importance as archival journals. Also, conference proceedings are not always well-indexed, making articles difficult to be "discovered" during keyword searches. Hence, our program has gradually transitioned to publishing the majority of the manuscripts in archival 
journals. Articles have been published in journals related to Humanitarian Engineering, Social Entrepreneurship, Telemedicine, Education, Agriculture, Systems Engineering, Design, Global Health, Engineering Education, Tourism, Biomedical Engineering, etc. A complete listing of publications is available on the program (and senior author's) website.

Our publication strategy is to target diverse journals so as to increase awareness about HESE. Journals with reasonable impact factors, distinguished editorial boards, and longer publishing history are preferred. The most important factor is indexing (especially on Google Scholar) so that the articles are likely to be discovered by others. Open access journals are preferred over paid journals so that the knowledge is accessible to a wider audience. Journals with exorbitant $(>\$ 300)$ publishing fees or print-only journals are avoided since their readership is typically very limited. Journals that are specifically geared for undergraduate research and publications are unacceptable. Our experience is that the majority of the applied journals are welcoming to HESE manuscripts. Journals that publish "hard" natural and social sciences are not appropriate for the vast majority of our articles. Some journals, and the communities they represent, dislike the market-centric (entrepreneurial) approach that forms the bedrock of our philosophy of engagement. In essence, the more open a journal is in terms of professions and sectors of authors and reviewers, cultures and countries represented on the editorial board, and manuscript types accepted, the more likely they are to consider our papers for peer evaluation. The biggest challenge to our publication enterprise is not the intellectual content of the articles, IRB policies, or a dearth of journals. Mentoring (mostly) undergraduate students with little research writing experience to write publication-quality articles is the biggest challenge followed by the atrocious timelines for peer review and publication. 